\title{
Selectivity in hydrodehalogenation of polychloro- and polybromobenzenes under multiphase conditions
}

\author{
Carlos Alberto Marques ${ }^{1}$, Olga Rogozhnikova, Maurizio Selva, Pietro Tundo * \\ Dipartimento di Scienze Ambientali, Università di Venezia, Cà Foscari, Calle Larga Santa Marta, 2137, 30123 Venice, Italy
}

Received 9 Septembcr 1994; accepted 4 November 1994

\begin{abstract}
The competitive hydrodehalogenation of isomeric $o$-, $m$ - and $p$-dichloro (and dibromo) benzenes with $\mathrm{H}_{2}$ at atmospheric pressure and $\mathrm{Pd} / \mathrm{C}$ or $\mathrm{Ni}-\mathrm{Raney}$ carried out in a multiphase system (organic solvent and $50 \% \mathrm{KOH}$ aq. solution) is influenced by the presence of a bulky quaternary onium salt where both the catalytic activity and the selectivity change in relation to the halogen to be removed and the metal catalyst used. In particular, the Ni-Raney catalyst becomes effective in the reduction only if an onium salt is added. Similarly, the onium salt effects the catalytic hydrodehalogenation of 1,2,4-trichloro- and 1,2,4tribromobenzene.
\end{abstract}

Keywords: Carbon; Hydrodehalogenation; Multiphase system; Ni-Raney; Onium salt; Palladium; Pd/C Selectivity

\section{Introduction}

Hydrodehalogenation reactions compared to other detoxification methods [1,2] are gaining importance because they allow the polyhalogenated aromatics to be reduced to the parent hydrocarbons without the production of waste. Moreover they may selectively remove the halogen from the aromatic ring, thus providing new methods for organic synthesis $[3,4]$.

We previously reported [5] that in the dehalogenations of aromatics catalyzed by palladium on carbon $(\mathrm{Pd} / \mathrm{C})$ with hydrogen at atmospheric pressure in a two-phase system (aqueous $\mathrm{KOH}$ and organic solvent), the presence of an onium salt as a phase-transfer (PT) catalyst could change both the catalytic activity and the selectivity in the

\footnotetext{
* Corresponding author.

${ }^{1}$ Supported by the National Council Research of Brazil (CNPq).
}

removal of the halides from different positions of the aromatic ring. For example, these reaction conditions allowed a very rapid hydrodechlorination on sterically hindered compounds (i.e., 2chloro-m-xylene and PCBs) [5]. In addition, in the presence of Aliquat 336 (tricaprylmethylammonium chloride, 1) an unusual selectivity occurred in the reduction of isomeric dichlorobenzenes carried out in diethyl ether at $20^{\circ} \mathrm{C}$ : the $o$ isomer reacted 5.3 times faster than the $p$-one.

We wish to report here that by varying the metallic catalyst under multiphase conditions, the onium salt considerably induces different reaction outcomes in the dehalogenation of polychloroand polybromobenzenes as well.

In particular, the catalytic activity and the selectivity of both $\mathrm{Pd} / \mathrm{C}$ and Ni-Raney are considered. At first, the reduction of $o-, m$ - and $p$-dichloro and dibromobenzene isomers are reported and then the 
trichloro- and tribromobenzene derivatives are studied.

The selectivity in the removal of different halogens bonded to the same aromatic ring is also discussed through the investigation of the reduction of 1-bromo-4-chloro-, 1-bromo-2,6dichloro-, and 1-bromo-3-fluoro-4-iodobenzene.

\section{Experimental}

\subsection{General}

All reagents and solvents were commercially available and were used without further purification. $5 \% \mathrm{Pd} / \mathrm{C}$ and $\mathrm{Ni}-\mathrm{Al}$ alloy were Fluka, Arts. Nos. 75992 and 72240 , respectively.

The metallic catalysts ( $\mathrm{Pd} / \mathrm{C}$ or $\mathrm{Ni}-\mathrm{Raney})$ was used according to the following molar ratios: (i) $\mathrm{Pd} / \mathrm{Cl}$ and $\mathrm{Pd} / \mathrm{Br}$ in the range of $0.0051-0.01$; (ii) $\mathrm{Ni} / \mathrm{Cl}$ and $\mathrm{Ni} / \mathrm{Br}$ in the range of $0.68-1.36$.

The mixtures were magnetically stirred at 1000 rpm in a $25 \mathrm{ml}$ three-necked round-bottomed thermostated flask, connected with a system for the addition of hydrogen. The reactions courses were followed by gas chromatography: comparison with authentic samples were done. The conversions were referred to the internal standard ( $n$ decane).

GC analyses were performed on a Varian GC 3400 using a fused silica capillary column (30 $\mathrm{m} \times 0.25 \mathrm{~mm}$ ) with DB-5 as the liquid phase (film thickness $0.25 \mathrm{~mm}$ ) and with a FID detector.

\subsection{Preparation of the Ni catalyst}

The Ni-Raney catalyst was prepared in situ as described in literature [6]: $\mathrm{Ni}-\mathrm{Al}$ powder $(0.235$ $\mathrm{g}, 2.0 \mathrm{mmol} \mathrm{Ni}$ ) was added to KOHaq. (50\%, 4 $\mathrm{ml}$ ) at 50 or $20^{\circ} \mathrm{C}$ and magnetically stirred for about 40 min until the evolution of $\mathrm{H}_{2}$ ceased. Then, in the same vessel, the reaction was started: the reagent solution and Aliquat 336 were added and $\mathrm{H}_{2}$ was bubbled at atmospheric pressure in the organic phase at about $1 \mathrm{ml} / \mathrm{min}$.

\subsection{Reduction procedures}

2.3.1. Competitive hydrodehalogenation reactions of isomeric dichloro- and dibromobenzenes with Pd/C or Ni-Raney catalyst - (Table 1)

A mixture of $\mathrm{KOH}$ (aq.) $(50 \%, 4 \mathrm{ml}), 7.0 \mathrm{ml}$ of organic solution (isooctane or $n$-pentane) of $o-, m$ - and $p$-dichlorobenzenes or dibromobenzenes (each at $0.07 \mathrm{M} ; 1.47 \mathrm{mmol}$ in total), the catalyst ( $5 \% \mathrm{Pd} / \mathrm{C}: 0.032 \mathrm{~g}, 0.015 \mathrm{mmol}$; NiRaney: $0.235 \mathrm{~g}, 2.0 \mathrm{mmol}$ ) and Aliquat 336 $(0.085 \mathrm{~g}, 0.20 \mathrm{mmol})$ was loaded into a $25 \mathrm{ml}$ three-necked round-bottomed flask and magnetically stirred at $1000 \mathrm{rpm}$. The flask was thermostated at 50 or $20 \pm 0.1^{\circ} \mathrm{C}$ and connected with a system for the inlet of $\mathrm{H}_{2}$; the latter was bubbled at atmospheric pressure in the organic phase at about $1 \mathrm{ml} / \mathrm{min}$. $n$-Decane was used as the internal standard.

\subsubsection{General procedure for hydrodehalogena-} tion of aryl halides with $\mathrm{Pd} / \mathrm{C}$ or Ni-Raney catalysts - (Tables 2-6)

An organic solution $(0.07 \mathrm{M})$ of each substrate (1,2,4-trichloro- and tribromobenzenes, 1bromo-4-chlorobenzene, 1-bromo-2,6-dichlorobenzene and 1-bromo-3-fluoro-4-iodobenzene) was prepared and $n$-decane was used as the internal standard.

A mixture of $\mathrm{KOH}($ aq. $)(50 \%, 4 \mathrm{ml})$, an organic solution of the substrate $(7 \mathrm{ml}, 0.49$ $\mathrm{mmol}$ ), the catalyst ( $5 \% \mathrm{Pd} / \mathrm{C}: 0.032 \mathrm{~g}, 0.015$ mmol; Ni-Raney: $0.245 \mathrm{~g}, 0.20 \mathrm{mmol}$ ) and Aliquat $336(0.085 \mathrm{~g}, 0.20 \mathrm{mmol})$ was loaded into a $25 \mathrm{ml}$ three-necked round-bottomed flask and magnetically stirred at $1000 \mathrm{rpm}$. The flask was thermostated at 50 or $20 \pm 0.1^{\circ} \mathrm{C}$ and connected with a system for the inlet of $\mathrm{H}_{2}$; the latter was bubbled at atmospheric pressure in the organic phase at about $1 \mathrm{ml} / \mathrm{min}$. $n$-Decane was used as the internal standard. 


\section{Results and discussion}

\subsection{Hydrodehalogenation of $o-, m$ - and $p$ - dichloro and dibromobenzene isomers}

The competitive hydrodehalogenation of the dichloro- and dibromobenzenes (DCBs and DBBs, respectively) was investigated first. When the three isomers $(o-, m$ - and $p-)$ are simultaneously reacted, a unique intermediate (chlorobenzene or bromobenzene) and a single final product (benzene) originate so that the kinetic constant for each compound can be easily determined. In fact, correct pseudo zero-order constants are obtained for each the three isomers (for both the dichlorobenzenes or the dibromo- ones). The results are reported in Table 1.

For simplicity, only the kinetic constant for the ortho-isomer is reported $\left(k_{\text {ortho }}\right)$ and the ratios $k_{\text {meta }} / k_{\text {ortho }}$ and $k_{\text {para }} / k_{\text {ortho }}$ are shown; that is, in entry 1 of Table $1, k_{\text {meta }}=k_{\text {ortho }} \times 1.04=66 \mathrm{M} / \mathrm{s}$ and $k_{\text {para }}=k_{\text {ortho }} \times 0.71=45 \mathrm{M} / \mathrm{s}$. The time required for the dichlorobenzene mixture to be reduced to benzene is also reported.

In the hydrodehalogenation of the $o-, m$ - and $p$ dichloro and dibromobenzene isomers, $\mathrm{Pd} / \mathrm{C}$ allows a faster reaction than Ni-Raney both at $50^{\circ} \mathrm{C}$ in isooctane and at $20^{\circ} \mathrm{C}$ in $n$-pentane (compare entries $1-4$ and 9-12 with 5-8 and 13-14, respectively). However, depending on the metal catalyst used, the presence of the onium salt has a remarkable effect. Particularly in the case of $\mathrm{Pd} /$ $\mathrm{C}$, when Aliquat 336 is used, a decrease in the reaction rate is observed (more evident at low temperatures with the dibromobenzenes; entries 11 and 12).

By contrast, the Ni-Raney catalyst expressly needs the presence of the PT agent for the reduction to occurs; otherwise, no reaction takes place (entries 6 and 8).

As we previously reported [5], under our multiphase conditions the PT agent coats the metal catalyst surface, so that it might intervene by modifying the adsorption process of the halogenated

Table 1

Competitive hydrodehalogenation of $o-, m$ - and $p$-dichloro- and dibromobenzenes under multiphase conditions ${ }^{\text {a }}$

\begin{tabular}{|c|c|c|c|c|c|c|c|c|}
\hline Entry & Substrate & Catalyst $^{\circ}$ & Solvent & PT agent ${ }^{\mathbf{c}}$ & $k_{\text {ortho }} \times 10^{4}\left(\mathrm{M} \mathrm{s}^{-1}\right)^{\mathrm{d}}$ & $\left(k_{\text {ortho }}: k_{\text {meta }}: k_{\text {para }}\right)^{c}$ & $t(\min )$ & $\%$ Benzene \\
\hline $1^{f}$ & DCBs & $\mathrm{Pd} / \mathrm{C}$ & Isooctane & 1 & 63.0 & $1.00: 1.04: 0.71$ & 60 & 100 \\
\hline $2^{f}$ & DCBs & & Isooctane & no & 97.0 & 1:00:1.03:1.01 & 50 & 99 \\
\hline $3^{f}$ & DCBs & & $n$-Pentane & 1 & 6.7 & $1.00: 1.05: 0.44$ & 130 & 99 \\
\hline $4^{f}$ & DCBs & & $n$-Pentane & no & 7.0 & $1.00: 0.93: 0.99$ & 110 & 92 \\
\hline 5 & DCBs & Ni-Raney & Isooctane & 1 & 4.0 & $1.00: 0.83: 0.64$ & 150 & 97 \\
\hline 6 & DCBs & & Isooctane & no & - & - & 180 & - \\
\hline 7 & DCBs & & $n$-Pentane & 1 & 0.6 & $1.00: 0.95: 0.60$ & 370 & 95 \\
\hline 8 & DCBs & & $n$-Pentane & no & - & -8 & 180 & - \\
\hline 9 & DBBs & $\mathrm{Pd} / \mathrm{C}$ & Isooctane & 1 & 4.4 & $1.00: 1.42: 1.50$ & 135 & 100 \\
\hline 10 & DBBs & & Isooctane & no & 16.0 & $1.00: 1.21: 1.50$ & 50 & 100 \\
\hline 11 & DBBs & & $n$-Pentane & 1 & 0.7 & $1.00: 2.00: 2.02$ & 360 & 70 \\
\hline 12 & DBBs & & $n$-Pentane & no & 12.5 & $1.00: 1.11: 1.08$ & 75 & 100 \\
\hline 13 & DBBs & $\mathrm{Ni-Raney}$ & Isooctane & 1 & 12.0 & $1.00: 0.79: 0.53$ & 80 & 100 \\
\hline 14 & DBBs & & $n$-Pentane & 1 & 2.5 & $1.00: 0.97: 0.22$ & 250 & 96 \\
\hline
\end{tabular}

a The reactions were carried out at $50^{\circ} \mathrm{C}$ in isooctane and $20^{\circ} \mathrm{C}$ in $n$-pentane and $\mathrm{Et}_{2} \mathrm{O}$. For details, see Experimental. $o$-, $m$ - and $p$-dichlorobenzenes: $0.21 \mathrm{M}(0.07 \mathrm{M}$ of each).

${ }^{b}$ Pd: $0.015 \mathrm{mmol}$ and $\mathrm{Ni}: 2.0 \mathrm{mmol}$.

${ }^{c} 1$ : Aliquat 336.

a Zero-order reaction rates for ortho-dichlorobenzene.

e Normalized ratios between corresponding rate constants for $o-, m$ - and $p$-isomers, respectively ( $k_{\text {orto }}$ is set equal to unity).

${ }^{\mathrm{f}}$ From [5]

${ }^{\mathcal{E}}$ No reduction after $180 \mathrm{~min}$. 
Table 2

Catalytic hydrodehalogenation of 1,2,4-trichlorobenzene under multiphase conditions *

\begin{tabular}{|c|c|c|c|c|c|c|c|c|c|c|c|}
\hline \multirow[t]{3}{*}{ Entry } & \multirow[t]{3}{*}{ Catalyst $^{\mathrm{b}}$} & \multirow[t]{3}{*}{ Solvent } & \multirow[t]{3}{*}{ PT agent ${ }^{c}$} & \multirow{3}{*}{$\begin{array}{l}T \\
\left({ }^{\circ} \mathrm{C}\right)\end{array}$} & \multirow{3}{*}{$\begin{array}{l}t \\
(\min )\end{array}$} & \multirow{3}{*}{$\begin{array}{l}\text { Conv. } \\
(\%)\end{array}$} & \multicolumn{5}{|c|}{ Yields (\%) } \\
\hline & & & & & & & \multicolumn{3}{|c|}{ Dichlorobenzenes d } & \multirow[t]{2}{*}{$\mathrm{PhCl}$} & \multirow[t]{2}{*}{$\mathrm{PhH}$} \\
\hline & & & & & & & ortho- & meta- & para- & & \\
\hline 1 & $\mathrm{Pd} / \mathrm{C}$ & Isooctane & 1 & 50 & $\begin{array}{c}30 \\
(35)\end{array}$ & $\begin{array}{c}96 \\
(100)\end{array}$ & $\begin{array}{c}6.0 \\
(2.0)\end{array}$ & $\begin{array}{l}2.5 \\
(-)\end{array}$ & $\begin{array}{l}1.5 \\
(-)\end{array}$ & $\begin{array}{c}3.0 \\
(1.0)\end{array}$ & $\begin{array}{c}83 \\
(97)\end{array}$ \\
\hline 2 & & Isooctane & no & 50 & 20 & 100 & 7.0 & 2.0 & 1.0 & 9.0 & 81 \\
\hline 3 & & Diethyl ether & 1 & 20 & 60 & 100 & 4.0 & 1.5 & 2.0 & 3.5 & 89 \\
\hline 4 & & Diethyl ether & no & 20 & 30 & 100 & 20.0 & 6.0 & 4.0 & 15.0 & $55^{\mathrm{e}}$ \\
\hline 5 & Ni-Raney & Isooctane & 1 & 50 & 150 & 100 & 26.0 & 15.0 & 11.0 & 38.0 & $10^{f}$ \\
\hline 6 & & Isooctane & no & 50 & 180 & 0 & - & - & - & - & $-\mathrm{B}$ \\
\hline 7 & & Diethyl ether & 1 & 20 & 360 & 79 & 32.0 & 18.0 & 11.0 & 11.0 & 7 \\
\hline 8 & & Diethyl ether & no & 20 & 180 & 0 & - & - & - & - & -8 \\
\hline
\end{tabular}

"For reaction conditions see Experimental. TCB: $0.07 \mathrm{M}$ (0.49 mmol).

${ }^{b} \mathrm{Pd} / \mathrm{C}: 0.015 \mathrm{mmol}$ and $\mathrm{Ni}: 2.0 \mathrm{mmol}$.

c 1: Aliquat 336.

'By gas chromatography; during the reactions 1-8 the distribution between the dichlorobenzenes remains unchanged.

e $100 \%$ after $50 \mathrm{~min}$.

' $99 \%$ after 450 min (see Fig. 1).

${ }^{\varepsilon}$ No reaction.

species and/or allowing different reaction environments. This effect seems to be crucial for the $\mathrm{Ni}-$ Raney catalyst.

In addition, DCBs (and also DBBs) are reduced at almost the same rate over $\mathrm{Pd} / \mathrm{C}$ in the absence of 1 . In its presence, a selective removal of the halogen is observed which varies according to the metal catalyst used. In fact, in the presence of Aliquat 336, the isomer reactivity of DCBs follows the order $o \cong m>p$; that is, the para isomer is always the least reactive both with $\mathrm{Pd} / \mathrm{C}$ and Ni-Raney (entries 1, 3, 5 and 7).
The same trend also holds in the hydrodebromination of DBBs over Ni-Raney (entries 13 and 14). Operating at $20^{\circ} \mathrm{C}$ the $p$-isomer reacts 4.5 fold slower than the ortho-one (entry 14).

When operating instead, with $\mathrm{Pd} / \mathrm{C}, 1$ induces a reverse reactivity on the $\mathrm{DBB}$ isomers by making the ortho derivative less reactive than the para one (entries 9 and 11). The effect is more pronounced at low temperatures (entry 11), where $o$-dibromobenzene reacts 2.0 fold slower than the $p$-dibromobenzene.

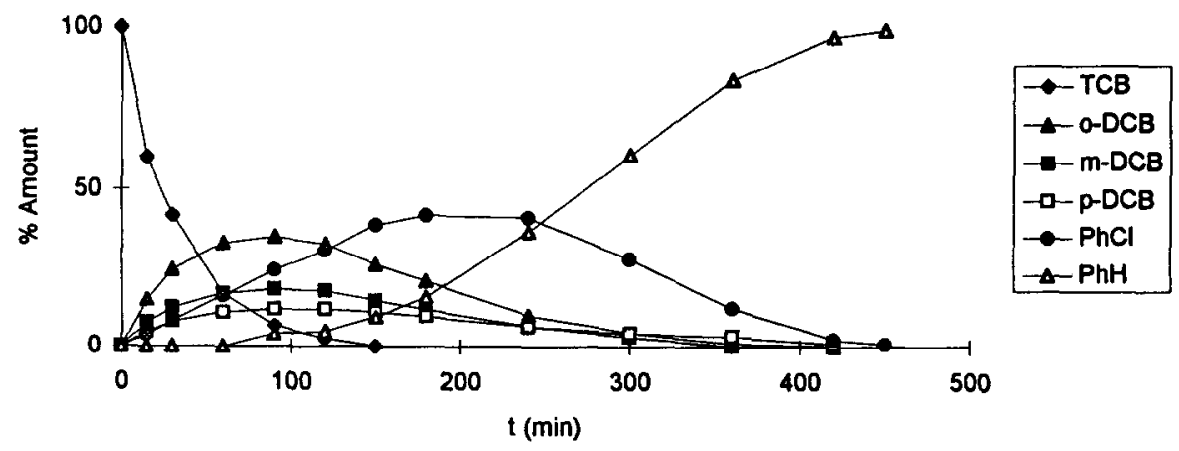

Fig. 1. Hydrodehalogenation of 1,2,4-trichlorobenzene in isooctane with Ni-Raney and Aliquat 336 (from Table 2, entry 5). 
Table 3

Catalytic hydrodehalogenation of 1,2,4-tribromobenzene under multiphase conditions a

\begin{tabular}{|c|c|c|c|c|c|c|c|c|c|c|c|}
\hline \multirow[t]{3}{*}{ Entry } & \multirow[t]{3}{*}{ Catalyst $^{b}$} & \multirow[t]{3}{*}{ Solvent } & \multirow[t]{3}{*}{ PT agent ${ }^{c}$} & \multirow{3}{*}{$\begin{array}{l}T \\
\left({ }^{\circ} \mathrm{C}\right)\end{array}$} & \multirow{3}{*}{$\begin{array}{l}t \\
(\min )\end{array}$} & \multirow{3}{*}{$\begin{array}{l}\text { Conv. } \\
(\%)\end{array}$} & \multicolumn{5}{|c|}{ Yields (\%) } \\
\hline & & & & & & & \multicolumn{3}{|c|}{ Dibromobenzenes $^{d}$} & \multirow[t]{2}{*}{$\mathrm{PhBr}$} & \multirow[t]{2}{*}{$\mathrm{PhH}$} \\
\hline & & & & & & & ortho- & meta- & para & & \\
\hline 1 & $\mathrm{Pd} / \mathrm{C}$ & Isooctane & 1 & 50 & 50 & 97 & 9.0 & 1.0 & - & 2.0 & 85 \\
\hline 2 & & Isooctane & no & 50 & 40 & 94 & 30.0 & 3.0 & 1.0 & 18.0 & $42^{\mathrm{e}}$ \\
\hline 3 & & $n$-Pentane & 1 & 20 & 270 & 100 & 7.0 & 1.0 & - & 6.0 & 86 \\
\hline 4 & & $n$-Pentane & no & 20 & 50 & 99 & 7.0 & 1.0 & - & 16.0 & $75^{f}$ \\
\hline 5 & Ni-Raney & Isooctane & $\mathbf{1}$ & 50 & $\begin{array}{c}10 \\
(40)\end{array}$ & $\begin{array}{c}100 \\
(100)\end{array}$ & $\begin{array}{c}1.0 \\
(0.5)\end{array}$ & $\begin{array}{c}24.0 \\
(12.0)\end{array}$ & $\begin{array}{c}61.0 \\
(30.0)\end{array}$ & $\begin{array}{c}14.0 \\
(56.5)\end{array}$ & $(\overline{1.0})^{\mathrm{g}}$ \\
\hline 6 & & Isooctane & no & 50 & 180 & 39 & 1.5 & 11.0 & 24.0 & 2.0 & - \\
\hline 7 & & Isooctane & 2 & 50 & 15 & 100 & 2.0 & 21.0 & 61.0 & 16.0 & $-{ }^{h}$ \\
\hline 8 & & Isooctane & 3 & 80 & 75 & 100 & 2.0 & 22.0 & 62.0 & 14.0 & $-i$ \\
\hline
\end{tabular}

a For reaction conditions see Experimental. TBB: $0.07 \mathrm{M}(0.49 \mathrm{mmol})$.

${ }^{b} \mathrm{Pd}$ : $0.015 \mathrm{mmol}$ and $\mathrm{Ni}: 2.0 \mathrm{mmol}$.

c 1: Aliquat 336; 2: $\mathrm{C}_{16} \mathrm{H}_{33} \mathrm{P}^{+} \mathrm{Bu}_{3} \mathrm{Br}^{-} ; 3: \mathrm{C}_{16} \mathrm{H}_{33} \mathrm{~N}^{+}\left(\mathrm{C}_{18} \mathrm{H}_{37}\right)_{3} \mathrm{Br}^{-}$.

${ }^{a} \mathrm{By}$ gas chromatography; during the reactions $1-8$ the distribution between the dibromohenzenes remains unchanged.

E $100 \%$ after $50 \mathrm{~min}$.

' $100 \%$ after $60 \mathrm{~min}$.

$96 \%$ after 300 min.

' $98 \%$ after $150 \mathrm{~min}$.

i $5 \%$ after $300 \mathrm{~min}$.

\subsection{Hydrodehalogenation of $1,2,4$ -}

trichlorobenzene and 1,2,4-tribromobenzene

In order to investigate the possible effects of the PT agent on the catalytic reduction of the polyhalogenated aromatics, several tests were per-

Table 4

Hydrodehalogenation of 1-bromo-4-chlorobenzene under multiphase conditions ${ }^{\mathrm{a}}$

\begin{tabular}{|c|c|c|c|c|c|c|}
\hline \multirow[t]{2}{*}{ Entry } & \multirow[t]{2}{*}{ Catalyst $^{\mathrm{b}}$} & \multirow[t]{2}{*}{ PT agent ${ }^{c}$} & \multirow{2}{*}{$\begin{array}{l}t \\
(\min )\end{array}$} & \multirow{2}{*}{$\begin{array}{l}\text { Conv. } \\
(\%)\end{array}$} & \multicolumn{2}{|c|}{ Yields (\%) } \\
\hline & & & & & $\mathrm{PhCl}$ & $\mathrm{Bz}$ \\
\hline 1 & $\mathrm{Pd} / \mathrm{C}$ & 1 & 35 & 100 & 69 & $31^{\mathrm{d}}$ \\
\hline 2 & $\mathrm{Pd} / \mathrm{C}$ & no & 50 & 97 & 88 & $9^{\mathrm{e}}$ \\
\hline 3 & Ni Raney & 1 & 90 & 100 & 80 & $20^{r}$ \\
\hline 4 & $\mathrm{Ni}$-Raney & no & - & - & - & $-\mathrm{g}$ \\
\hline
\end{tabular}

${ }^{a}$ All reactions were carried out in isooctane solution at $50^{\circ} \mathrm{C}$. For details, see Experimental. $0.07 \mathrm{M}(0.49 \mathrm{mmol})$ of substrate.

${ }^{b} \mathrm{Pd}: 0.015 \mathrm{mmol}$ and $\mathrm{Ni}: 2.0 \mathrm{mmol}$.

${ }^{c} 1$ : Aliquat 336.

d $100 \%$ after $50 \mathrm{~min}$.

e $100 \%$ after $70 \mathrm{~min}$.

${ }^{f}$ After $330 \mathrm{~min}$ : (5\%) $\mathrm{PhCl}$ and (95\%) benzene.

${ }^{z}$ No reduction after $360 \mathrm{~min}$. formed under multiphase conditions on 1,2,4-trichlorobenzene (TCB) and 1,2,4-tribromobenzene (TBB) using both $\mathrm{Pd} / \mathrm{C}$ and $\mathrm{Ni}-$ Raney (Scheme 1).

In this case, due to the occurrence of consecutive dehalogenation reactions, in place of the

Table 5

Hydrodehalogenation of 1-bromo-2,6-dichlorobenzene in multiphase systems a

\begin{tabular}{|c|c|c|c|c|c|c|c|}
\hline \multirow[t]{2}{*}{ Entry } & \multirow[t]{2}{*}{ Catalyst $^{b}$} & \multirow{2}{*}{$\begin{array}{l}\text { PT } \\
\text { agent }\end{array}$} & \multirow{2}{*}{$\begin{array}{l}t \\
(\min )\end{array}$} & \multirow{2}{*}{$\begin{array}{l}\text { Conv. } \\
(\%)\end{array}$} & \multicolumn{3}{|c|}{ (\%) Yields } \\
\hline & & & & & $m-\mathrm{DCB}^{\mathrm{d}}$ & $\mathrm{PhCl}^{\text {d }}$ & $\mathrm{Bz}^{\mathrm{d}}$ \\
\hline 1 & $\mathrm{Pd} / \mathrm{C}$ & 1 & 80 & 100 & 23 & 8 & $69^{e}$ \\
\hline 2 & $\mathrm{Pd} / \mathrm{C}$ & no & 35 & 99 & 25 & 16 & $58^{f}$ \\
\hline 3 & $\mathrm{Ni}-$ Raney & 1 & 10 & 100 & 100 & 0 & $0^{g}$ \\
\hline 4 & Ni-Raney & no & 180 & 10 & 10 & 0 & 0 \\
\hline
\end{tabular}

${ }^{\text {a }}$ All reactions were carried out in isooctane solution at $50^{\circ} \mathrm{C}$. For details, see Experimental. $0.07 \mathrm{M}(0.49 \mathrm{mmol})$ of substrate.

${ }^{b}$ Pd: $0.015 \mathrm{mmol}$ and $\mathrm{Ni}: 2.0 \mathrm{mmol}$.

c 1: Aliquat 336.

${ }^{d} \mathrm{DCB}, \mathrm{PhCl}$ and $\mathrm{Bz}$ : $m$-dichlorobenzene, chlorobenzene and benzene, respectively.

e $100 \%$ after $120 \mathrm{~min}$.

f $100 \%$ after $45 \mathrm{~min}$.

${ }^{g}$ After 300 min: $m$-DCB (80\%) and $\mathrm{PhCl}$ (20\%). 


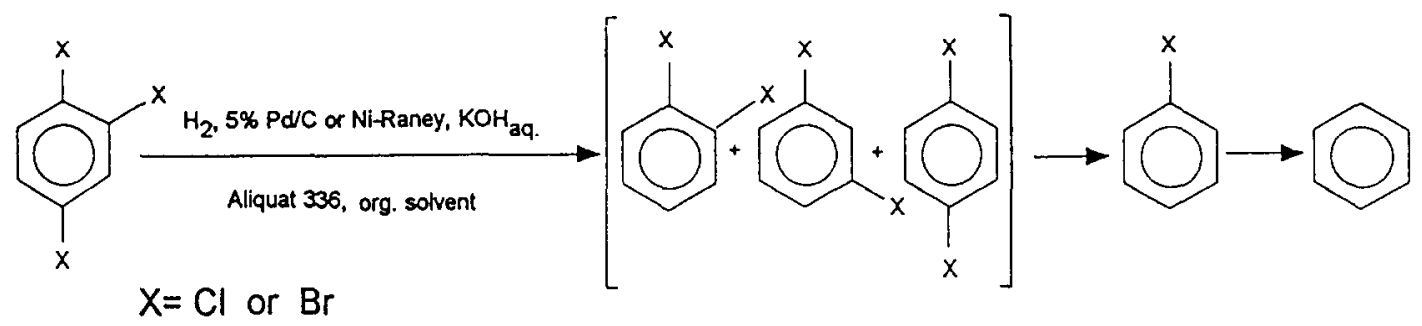

Scheme 1.

kinetic constants (not calculated), the conversion of the reagent (at a time) and the yields of the diand monohalogenated derivatives were determined.

Table 2 reports the results of the hydrodechlorination of TCB. As for the DCBs and DBBs, Pd/C is a more active catalyst than Ni-Raney in the reduction of TCB, and the reactions take place over Ni-Raney only if $\mathbf{1}$ is present (entries 5-8).

Where selectivity is concerned, only modest differences are detectable among the 1-, 2- and 4positions and no great effects derive from the onium salt. However, at complete TCB conversion, a higher amount of $o$-DCB is always obtained both with Pd and Ni. The 4-position (the less hindered one) reacts first. In all cases the observed reactivity order is 4->1->2-position.

Moreover, $\mathrm{Pd} / \mathrm{C}$ is actually more active than $\mathrm{Ni}$ in the $\mathrm{PhCl}$ reduction. In fact, when TCB has disappeared, a higher amount of $\mathrm{PhCl}$ remains in the reaction mixture if $\mathrm{Ni}$ is the catalyst (entries 5 and 7). The course of the reaction of entry 7 is shown in Fig. 1.

Table 3 reports the results of the hydrodehalogenation of TBB. The influence of onium salt on both catalytic activity and selectivity is relevant here. The reaction is slowed down by the presence of 1 in the case of $\mathrm{Pd} / \mathrm{C}$ (entries 1-4). This effect becomes much clearer at low temperatures (entries 3-4). Instead, while the reduction of TBB to DBBs over Ni-Raney occurs slowly in the absence of the onium salt (entry 6), the coupling of Ni-Raney and 1 allows the TBB reduction to proceed very quickly giving a mixture of DBBs. The reaction appears even more rapid than the one carried out over $\mathrm{Pd} / \mathrm{C}$ alone (compare entry 2 with entry 5).

Where position selectivity is concerned, a trend similar to the DCBs is observed (that is, 4->1$>2$-position) using $\mathrm{Pd} / \mathrm{C}$. Instead, an opposite result occurs for the Ni-Raney catalyst where at complete TBB conversion, the yield ratio of the ortho to the para isomer is 60:1 (entry 5). That is, despite the higher steric hindrance, the bromine atom in the 2-position, is markedly the most reactive and hydrodebromination reactivity follows the order 2->1->4-position. Although less evident, this trend remains remarkable also with other PT agents (entries 7 and 8).

When the TBB has disappeared, both the further reduction of the $\mathrm{DBBs}$ mixture and the $\mathrm{PhBr}$ proceed slower with Ni-Raney than with $\mathrm{Pd} / \mathrm{C}$ (entries 2, 5 and 7-8; notes $\mathrm{e}-\mathrm{i}$ ). That is, $\mathrm{Pd} / \mathrm{C}$ is actually more active catalyst for the reduction of less halogenated aromatics (Table 2, entries 1-4; Table 3, entries 1-4) and the monohalogenated $\mathrm{PhBr}$ (as discussed for $\mathrm{PhCl}$ in Table 2).

\subsection{Hydrodehalogenation of 1-bromo-4- chlorobenzene, 1-bromo-2,6-dichlorobenzene and 1-bromo-3-fluoro-4-iodobenzene}

Other hydrodehalogenation reactions were carried out to examine if halogen bonded selectivity could arise from the use of different metal catalysts and the presence of an onium salt.

Tables 4 and 5 report the results of the hydrodehalogenation of 1-bromo-4-chlorobenzene (BCB) and 1-bromo-2,6-dichlorobenzene (BDCB). Bromine is the first halogen to be removed using both $\mathrm{Pd} / \mathrm{C}$ and Ni-Raney. Despite 

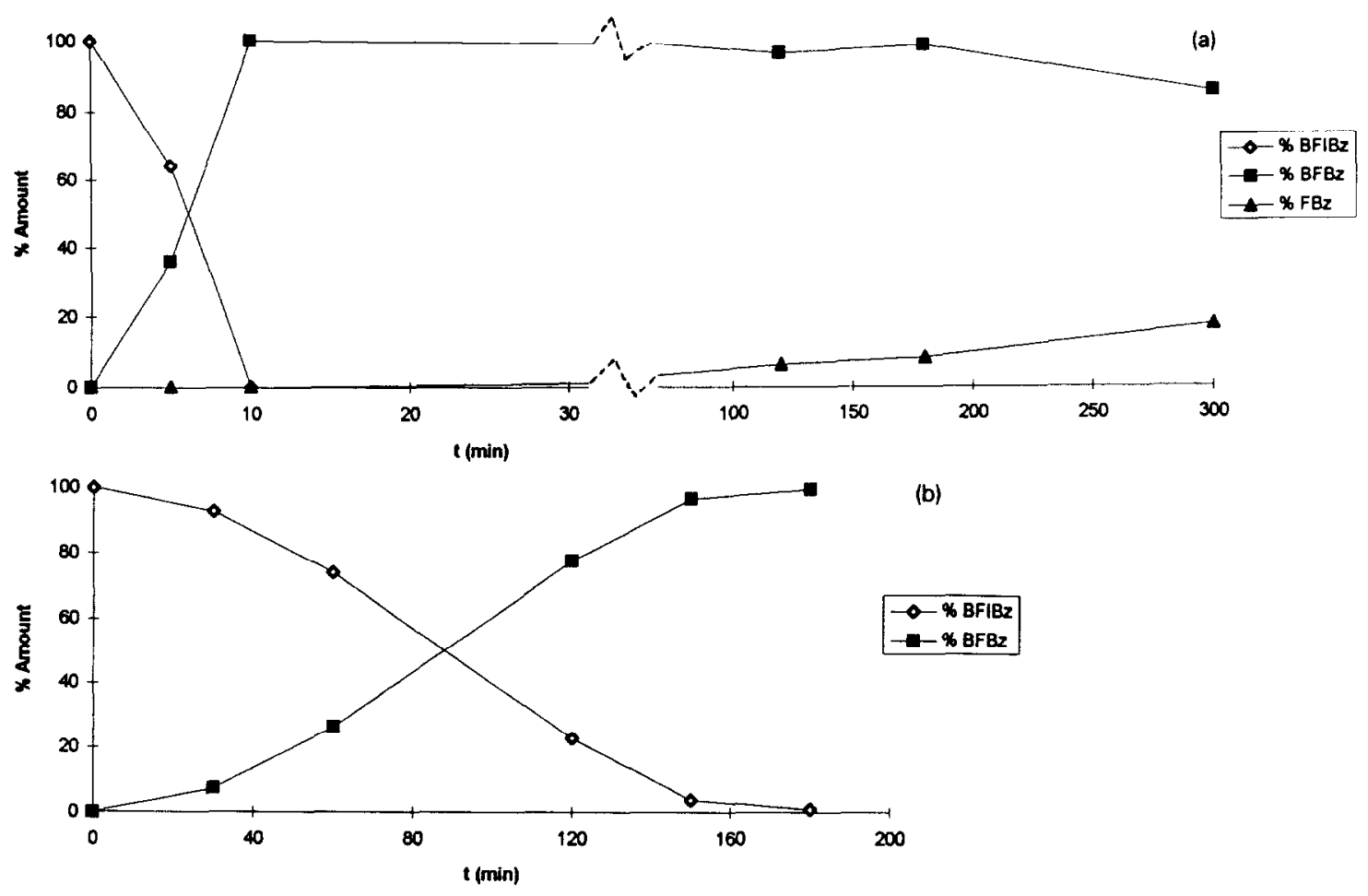

(b)

Fig. 2. (a) Hydrodehalogenation of 1-bromo-3-fluoro-4-iodobenzene (BFIBz) with Ni-Raney and Aliquat 336 (from Table 6, entry 3). (b) Hydrodehalogenation of 1-bromo-3-fluoro-4-iodobenzene (BIFBz) with Ni-Raney and without Aliquat 336 (from Table 6, entry 4).

the higher steric hindrance, the effect is more evident when BDCB is the substrate. In the case of the Ni catalyst, in particularly, the very rapid and

Table 6

Hydrodehalogenation of 1-bromo-3-fluoro-4-iodobenzene under multiphase conditions ${ }^{\text {a }}$

\begin{tabular}{|c|c|c|c|c|c|c|}
\hline \multirow[t]{2}{*}{ Entry } & \multirow[t]{2}{*}{ Catalyst $^{b}$} & \multirow{2}{*}{$\begin{array}{l}\text { PT } \\
\text { agent }^{c}\end{array}$} & \multirow{2}{*}{$\begin{array}{l}t \\
(\min )\end{array}$} & \multirow{2}{*}{$\begin{array}{l}\text { Conv. } \\
(\%)\end{array}$} & \multicolumn{2}{|c|}{ Yields (\%) } \\
\hline & & & & & $\mathrm{BFB}^{\mathrm{d}}$ & $\mathrm{FB}^{\mathrm{e}}$ \\
\hline 1 & $\mathrm{Pd} / \mathrm{C}$ & 1 & 210 & 98 & 98 & $0^{f}$ \\
\hline 2 & $\mathrm{Pd} / \mathrm{C}$ & no & 45 & 100 & 87 & $13^{g}$ \\
\hline 3 & Ni-Raney & 1 & 10 & 100 & 100 & $0^{\mathrm{h}}$ \\
\hline 4 & Ni-Raney & no & 180 & 99 & 99 & $0^{i}$ \\
\hline
\end{tabular}

a All reactions were carried out in isooctane solution at $50^{\circ} \mathrm{C}$. For details, see Experimental. $0.07 \mathrm{M}(0.49 \mathrm{mmol})$ of substrate.

${ }^{\mathrm{b}} \mathrm{Pd} / \mathrm{C}$ : $0.015 \mathrm{mmol}$ and $\mathrm{Ni}: 2.0 \mathrm{mmol}$.

c 1: Aliquat 336.

${ }^{\mathrm{d}}$ BFB: 1-bromo-3-fluorobenzene.

${ }^{e} \mathrm{FB}$ : fluorobenzene.

${ }^{\mathrm{f}}$ After 330 min only FB was present.

$100 \%$ FB after 60 min and after $300 \mathrm{~min} 93 \% \mathrm{FB}$ and $7 \%$ benzene.

${ }^{h}$ After $300 \mathrm{~min} 83 \%$ BFB and $17 \%$ FB.

${ }^{1}$ After 360 min $100 \%$ BFB. selective bromine removal gives the pure $m$-DCB in the reaction mixture (entry 3 , Table 5). Once again, the presence of onium salt 1 allows the NiRaney to be an effective and selective catalyst in the hydrodehalogenation reaction.

In addition, where selectivity is concerned, the effect of the halide anions originated from the reaction has also been considered. It is a well known concept in PT catalysis that quaternary onium salts allow a fast anion exchange between the two immiscible liquid phases. Moreover, if lipophilic anions are involved (e.g. $\mathrm{I}^{-}$), they are selectively transferred into the organic phase as counterions of the quaternary cations. Bearing this in mind, the hydrodehalogenation of 1-bromo-3fluoro-4-iodobenzene (BFIBz) was investigated under our multiphase conditions. Table 6 reports the results.

In all cases, iodine is the first halogen to be removed. However, when $\mathrm{Pd} / \mathrm{C}$ is the catalyst, an impressive decrease in catalytic activity results if 
Aliquat is used (entry 1 and 2, Table 6). This bahavior well parallels our previously reported observation [5]: the known poisoning effect of $\mathrm{I}^{-}$on the Pd catalyst is markedly enhanced by the onium salt. In covering the metallic surface, the $\mathrm{PT}$ agent allows a higher $\mathrm{I}^{-}$concentration on $\mathrm{Pd}$ thus inhibiting the further coordination with the reactants.

When Ni-Raney is used, the iodine removal is surprisingly rapid in the presence of 1 (entry 3, Table 6). However, immediately after hydrodeiodination is completed, a powerful inhibiting effect occurs. Fig. 2a-b clearly shows the course of the reaction. The reason of such different behaviour is unclear at the moment.

Although less evident with $\mathrm{Br}^{-}$anions (less lipophilic than $\mathrm{I}^{-}$), the same effect might also be responsible for the slowing down of the TBB reduction (Table 3 ) and the selectivity in the $m$ DCB formation during the BDCB dehalogenation (Table 6), both situations occurring after an initial debromination.

\section{Conclusion}

Under the investigated multiphase conditions, the presence of an onium salt markedly influenced the hydrodehalogenation of aromatics according to the compound to be reduced and the metal catalyst utilized.

The Ni-Raney catalyst is less active than the $\mathrm{Pd} / \mathrm{C}$ one, since a high quantity of the former has to be used. Ni-Raney is also less active on monoand dihalogenated benzenes; nevertheless, this may be particularly profitable to obtain selectively the less halogenated compounds when highly halogenated aromatics are reacted.

Different effects may result from the presence of the PT catalyst:

(1) Being adsorbed on the surface of the catalyst, the onium salt may mediate both the anion and the reagent/product exchanges with the two immiscible organic and aqueous phases. During the reaction, the originated halide anions may be quickly transferred into the aqueous phase thus allowing catalyst regeneration (the metal surface being otherwise poisoned by the presence of the $\mathrm{HX}$ ). In addition, the adsorbed onium salt provides a different reaction environment. This latter seems particularly suitable for the reactions using Ni-Raney, where reductions proceed (or proceed much better) only if the onium salt is present. Instead, the reaction rate is always depressed by the PT agent in the hydrodehalogenations carried out over $\mathrm{Pd} / \mathrm{C}$.

However, in all cases (both for $\mathrm{Ni}$ and Pd), the selectivity in the removal the halogen manifests itself only when the onium salt is present.

(2) The onium salt allows the influence of lipophilic anions (e.g., $\mathrm{I}^{-}, \mathrm{Br}^{-}$) to be more efficient on the catalytic centers because it selectively transfers these anionic species from the aqueous phase to the metal catalyst. In our case, the effect of $\mathrm{I}^{-}$is very clear: its presence together with the onium salt greatly inhibits the further debromination and dechlorination reactions, as shown in Fig. 2a-b.

It may be concluded that a proper combination of metal catalyst, onium salt and anionic species (produced or externally added into the reaction mixture) might give rise to the appropriate reaction environment to achieve high selectivity in halogen removal. In line with this, understanding of the reaction mechanisms will be crucial to elucidate the particular role of the PT agent.

In any case, the reported reactions represent a useful decontamination procedure for halogen removal from aromatics; in particular, the conditions described here may extend the application of Ni-Raney as an hydrodehalogenation catalyst [7].

In addition, the observed selectivity may render the method promising to give halogenated compounds not easily synthetized by direct electrophilic halogenation.

\section{Acknowledgements}

This work was supported by the Ministero Università e Ricerca Scientifica e Tecnologica, 
Fondo $40 \%$ and the University of Venice for a Study Grant of O.R.

\section{References}

[1] (a) P.N. Rylander, Catalytic Hydrogenation in Organic Synthesis, Academic Press, New York, 1973, p. 235-248; (b) A.P.G. Kieboom, F. Van Rantwijk, Hydrogenation and Hydrogenolysis in Synthetic Organic Chemistry, Delft University Press, Delft, 1977; (c) R.F. Heck, Palladium Reagents in Organic Synthesis: Best Synthetic Methods, Vol. I, Academic Press, Orlando, FL, 1985, p. 415-418.
[2] (a) P. Dini, J.C.J. Bart and N. Giordano, J. Chem. Soc., Perkin Trans. 2, (1975) 1479; (b) R.B. La Pierre, D. Wu, W.L. Kranich and A.H. Weiss J. Catal., 52 (1978) 59-71; (c) R.B. La Pierre, D. Wu, W.L. Kranich and A.H. Weiss J. Catal., 52 (1978) 218 229; (d) R.B. La Pierre, D. Wu, W.L. Kranich and A.H. Weiss J. Catal., 52 (1978) 230-238.

[3] C.A. Marques, M. Selva and P. Tundo, J. Chem. Soc., Perkin Trans I, 4 (1993) 529.

[4] C.A. Marques, M. Selva and P. Tundo, J. Org. Chem., 58 ( 1993) 5256.

[5] C.A. Marques, M. Selva and P. Tundo, J. Org. Chem., 59 (1994) 3830.

[6] A.A. Pavlic and H.J. Adkins, J. Am. Chem. Soc., 68 (1946) 1471.

[7] N.P. Buu-Hoi, N. Dat Xuong and N. Van Bar, Bull. Soc. Chem. Fr., (1963) 2442 